\title{
Prevalence of renal dysfunction among HIV infected patients receiving Tenofovir at Mulago: a cross-sectional study
}

\author{
Louis Nyende ${ }^{1 *}$ (D), Robert Kalyesubula², Emmanuel Sekasanvu ${ }^{2,3}$ and Pauline Byakika-Kibwika²
}

\begin{abstract}
Background: There is an increasing burden of non-communicable disease globally. Tenofovir disoproxil fumarate (TDF) is the most commonly prescribed antiretroviral drug globally. Studies show that patients receiving TDF are more prone to renal dysfunction at some point in time during treatment. Evaluation of kidney function is not routinely done in most HIV public clinics. Identification of renal dysfunction is key in resource constrained settings because managing patients with end stage renal disease is costly.
\end{abstract}

Method: This was a cross-sectional study conducted at an outpatient clinic in 2018 involving patients on TDF for at least 6 months who were 18 years or older. Patients with documented kidney disease and pregnancy were excluded. Estimated glomerular filtration rate (eGFR) was calculated using the CKD-Epi formula. Renal dysfunction was defined as any of the following; either eGFR $<60 \mathrm{~mL} / \mathrm{min} / 1.73 \mathrm{~m}^{2}$,or proteinuria of $\geq 2^{+}$on urine dipstick, glycosuria with normal blood glucose. Electrolyte abnormalities were also documented.

Results: We enrolled 278 participants. One hundred sixty nine (60.8\%) were females, majority $234(84.2 \%)$ were $<50$ years old, 205 (73.74\%) were in WHO stage 1, most participants 271(97.5\%) in addition to TDF were receiving lamivudine/efavirenz. The median age was 37(IQR 29-45) years; median duration on ART was 36 (IQR 24-60) months. The prevalence of renal dysfunction was $2.52 \%$ (7/278). Most noted electrolyte abnormality was hypocalcaemia (15.44\%).

Conclusions: The prevalence of renal dysfunction was low though some participants had hypocalcaemia. Screening for kidney disease should be done in symptomatic HIV infected patients on TDF.

Keywords: Renal dysfunction, Tenofovir disproxil fumarate, Estimated glomerular filtration rate

\section{Background}

People living with HIV (PLHIV) are living longer and as a result face a challenge of increasing morbidity from non-communicable diseases-NCDS [1,2]. Kidney disease manifesting as renal dysfunction is one of the emerging NCDs in the world, with a varying prevalence of 13.9 to $48.5 \%[3,4]$. There is increasing concern that HIV being epidemic in this region, is contributing to the increasing

\footnotetext{
* Correspondence: Inyende@gmail.com

${ }^{1}$ KCCA- directorate of public health, P.O. Box 7010, Kampala, Uganda

Full list of author information is available at the end of the article
}

prevalence of renal dysfunction in Sub-Saharan Africa [3] The etiology of renal dysfunction includes; HIVassociated nephropathy (HIVAN), HIV immune complex kidney disease (HIVICK), drugs used for treatment of opportunistic infections, antiretroviral therapy (ART), use of non-steroidal anti-inflammatory drugs (NSAIDS), herbal medicines, other co morbid conditions namely diabetes mellitus, hypertension and Hepatitis B \& C. The consequences of renal dysfunction range from acute kidney injury (AKI), chronic kidney disease, end stage renal disease (ESRD) or death [5]. In countries with 
limited resources curative services for NCDs are an obvious strain to government rendering prevention as the best strategy $[4,6,7]$. Prevention involves identifying those conditions early, continuous health education/ screening of the affected people and appropriate referral for proper management to delay complications.

The 90-90-90 UNAIDS strategy by 2020 [8] is not far away, but with it more people will be on ART coupled with the "test and treat approach", whereby an individual testing positive for HIV is initiated on ART regardless of the CD4 or WHO clinical stage [9]. People living with HIV will be on ART for a long time yet with advancing age renal dysfunction deteriorates [10]. When ART programs started in Uganda, there was a lot of emphasis on initial evaluation of patients before starting treatment, but as the number of patients has increased this has not always been the case [11]. With regard to ART, patients on Tenofovir disproxil fumarate (TDF)based regimen from a number of studies are more prone to decline in kidney function. Other factors associated with renal dysfunction include, being older, being female, AfricanAmerican ethnicity, low weight, low CD4 count, high viral load and having co-morbid conditions [12]. The cost of managing a patient with ESRD is high yet early identification with simply estimating glomerular filtration rate and a urine dipstick can help. The problem is even made worse by presentation of renal dysfunction being asymptomatic, late patient presentation, having few nephrologists and few/costly renal replacement therapies [13]. There are few studies quantifying the magnitude of renal dysfunction among HIV positive patients in sub-Saharan Africa and no renal registries/inadequate data in the region $[14,15]$. This study aimed to quantify the magnitude of renal dysfunction among HIV infected patients receiving TDF based ART.

\section{Methods \\ Study site}

The study was carried out at the Mulago Communicable Disease Clinic under the directorate of medicine situated in Kampala, Uganda. MulagoKiruddu hospital is home to the directorate of medicine since May 2016; running different medical outpatient and inpatient clinics. The communicable disease clinic is supported by Makerere University Joint AIDS Program (MJAP), runs on Fridays as an outpatient clinic, and mainly attends to HIV infected patients. All services are provided free of charge to the public.

\section{Study design}

We conducted a cross sectional study with the sample size calculated based on the Kish and Leslie formula for prevalence studies. The sample size was calculated as 396 (based on prevalence of 18.6,Wantakisha et al) [16] at a precision $\alpha$ of 0.05 .We included adults aged 18 years and above on TDF based ART for at least 6 or more months. Participants were enrolled consecutively for convenience of which 278 met the inclusion criteria. Reasons for exclusion included; being on TDF for less than 6 months, pregnancy and refusal to join the study (Reasons given included; limited time, need to consult spouse, no interest in participating in the study and some were already in other studies).

\section{Study procedures}

Patients, who fulfilled the study criteria were enrolled, interviewed for demographic and social data. Medical history was collected and physical examination performed. Blood pressure measurement was done in standard way (after patient had rested for $5 \mathrm{~min}$, in sitting position and two measurements were taken). Patients with a value greater than $140 / 90 \mathrm{mmHg}$ were considered hypertensive. Blood pressure $>140 \mathrm{mmHg}$ was considered systolic hypertension and a value of $>90 \mathrm{mmHg}$ considered diastolic hypertension. Nutritional assessment was done using body mass index (BMI), obtained using the formula body weight in kilograms divided by height squared in meters. Venous blood was collected for renal function test and electrolytes (serum creatinine, urea, potassium, calcium and phosphate). Reference laboratory ranges for electrolytes;

- Potassium 3.5-5.0 mmol/l

- Calcium 2.2-2.7 mmol/l

- Phosphate 0.97-1.45 mmol/l

Results for the electrolytes were reported as hypo or hyper depending on these reference ranges.

Following aseptic technique, $10 \mathrm{~mL}$ of venous blood was drawn from each participant into a syringe. Seven mills ( $7 \mathrm{mls}$ ) (of the 10mls) of blood for renal function tests \& electrolytes (potassium, calcium phosphate) was placed in a red top vacutainer and centrifuged. Four mls of serum were then put in crial vials. The remaining 3 $\mathrm{mls}$ (of the $10 \mathrm{~mL}$ ) were placed in a grey vacutainer bottle (to determine blood sugar). All these were adequately packaged in Ziploc bags and carrier for processing in old Mulago clinical laboratory. Renal function tests, electrolytes and blood sugar were determined using an automated Abott Machine, Architect plus-Ci Chemistry and immunochemistry analyzer.

Each participant was provided with a sterile urine container and educated briefly about provision of $20 \mathrm{~mL}$ of a mid-stream urine which was analyzed using a dipstick on the same day to determine presence of leucocytes, nitrites, hematuria or glucose. Estimated glomerular 
filtration rate (eGFR) was calculated using the Chronic kidney Disease Epidemiology Collaboration (CKD-EPI) formula which is more accurate than the Cockcroft gault formula [17]. For this study renal dysfunction was noted as either eGFR less than $60 \mathrm{ml} / \mathrm{min} / 1.73 \mathrm{~m}^{2}$ or proteinuria of $\geq 2^{+}$with glycosuria but normal blood sugar. As per Kidney foundation's kidney Disease outcome quality Initiative (K/DOQI),eGFR $<60$ for 3 months implies chronic kidney disease [6]. To capture patients of TDF nephrotoxicity we assessed proteinuria,glucosuria and serum glucose [18].

\section{Statistical analysis}

Data was analyzed using STATA 14.0 software package. Continuous variables were summarized as means and standard deviation for normally distributed data, medians and interquartile ranges for not normally distributed data. Categorical variables were summarized as frequencies, percentages and also in tables and figures. Tests for the significance of association were made using the Pearson chi-square $\left(X^{2}\right)$ test for categorical variables and independent sample $t$ test for continuous variables. The outcome variable was renal dysfunction.

\section{Results}

From November 2017 through March 2018 (for 4 months), eight hundred eight (808) patients were consecutively screened in Mulago Communicable Disease Clinic for study enrolment. Three hundred five (305) patients met the eligibility criteria and were enrolled. Of these, 278 were entered into the final analysis and 27 patients were excluded due to incomplete data. One hundred sixty nine (60.8\%) were female, majority 234 $(84.2 \%)$ were $<50$ years old. Median age was 37 (IQR 29-45) years. One hundred nineteen (42.81\%) were married, $141(50.72 \%)$ had a primary education, $250(89.93 \%)$ had formal employment, 252(83.45\%) resided in Kampala and 81 (29.14\%) consumed alcohol. (Table 1).

\section{Clinical and laboratory characteristics (Table 2)}

The median duration on ART was 36 IQR (24-60) months, 271 (97.48\%) were on TDF/3TC/EFV, 152(72.38\%) had CD4 $\geq 200$ cells/ml, 109 (86.51\%) had viral load of $<1000$ copies $/ \mathrm{ml}, 205(73.74 \%)$ were in WHO clinical one,155(55.76\%) had a normal BMI, 38(13.67\%) had systolic hypertension, 42(15.11\%) had diastolic hypertension and 270(97.12\%) had no concurrent opportunistic infections. Three (1.08\%) had random blood sugar $\geq 11.1 \mathrm{mmol} / \mathrm{l}, 10$ (3.6\%) had proteinuria of $\geq 2^{+}, 4(1.44 \%)$ tested positive for nitrites, $7(2.52 \%)$ had hematuria and $2(0.72 \%)$ had glycosuria.
Table 1 Socio-demographic Characteristics of the study participants receiving TDF based ART $\geq 6$ months at Mulago Communicable disease clinic

\begin{tabular}{|c|c|c|}
\hline Socio-demographics & Frequency(n) & Percentage (\%) \\
\hline \multicolumn{3}{|l|}{ Gender } \\
\hline Male & 109 & 39.21 \\
\hline Female & 169 & 60.79 \\
\hline Age (Years) median,(IQR) & $37(29-45)$ & \\
\hline $18-34$ & 128 & 46.04 \\
\hline $35-49$ & 106 & 38.13 \\
\hline$\geq 50$ & 234 & 84.17 \\
\hline \multicolumn{3}{|l|}{ Marital status } \\
\hline Single & 51 & 18.35 \\
\hline Married & 119 & 42.81 \\
\hline Separated & 85 & 30.58 \\
\hline Widowed & 23 & 8.27 \\
\hline \multicolumn{3}{|l|}{ Education level } \\
\hline Primary & 141 & 50.72 \\
\hline Secondary & 115 & 41.37 \\
\hline Tertiary & 22 & 7.91 \\
\hline \multicolumn{3}{|l|}{ Occupation } \\
\hline Unemployed & 28 & 10.07 \\
\hline Employed & 250 & 89.93 \\
\hline \multicolumn{3}{|l|}{ Address } \\
\hline Outside Kampala & 46 & 16.55 \\
\hline Within Kampala & 232 & 83.45 \\
\hline \multicolumn{3}{|l|}{ Alcohol } \\
\hline No & 197 & 70.86 \\
\hline Yes & 81 & 29.14 \\
\hline
\end{tabular}

Electrolyte abnormalities among study participants (Table 3)

Ten (3.59\%) had hypophosphatemia, 11(4.44\%) had hyperphosphatemia, $15(5.26 \%)$ had hyperkalemia, $3(1.32 \%)$ had hypokalemia, 43 (15.44\%) had hypocalcaemia and $2(0.67 \%)$ had hypercalcemia.

Prevalence of renal dysfunction among study participants Of the 278 subjects, 7 were found to have eGFR $<60 \mathrm{ml} /$ $\min / 1.73 \mathrm{~m}^{2}$, ten [10] patients had proteinuria (but no glycosuria), 2 patients had glycosuria (but no proteinuria). Therefore prevalence of renal dysfunction was 2.52\% (7/278). (See Table 4).

\section{Discussion}

We aimed to determine the prevalence of renal dysfunction among HIV infected patients receiving TDF attending Mulago Communicable Disease Clinic in Uganda. Defining renal dysfunction as eGFR $<60 \mathrm{~mL} / \mathrm{min} / 1.73$ $\mathrm{m}^{2}$ or proteinuria of $\geq 2^{+}$, with glycosuria on dip stick 
Table 2 Clinical characteristics of the study participants receiving TDF based ART $\geq 6$ months at Mulago Communicable Disease Clinic

\begin{tabular}{|c|c|c|}
\hline Characteristics & Frequency $(\mathrm{n})$ & Percentage (\%) \\
\hline \multicolumn{3}{|l|}{$\overline{\mathrm{BMI}}$} \\
\hline 18.5-24.9-Normal & 155 & 55.76 \\
\hline 25-29.9- Overweight & 78 & 28.06 \\
\hline$\geq 30$ - Obese & 24 & 8.63 \\
\hline \multicolumn{3}{|l|}{ Systolic hypertension } \\
\hline No & 240 & 86.33 \\
\hline Yes & 38 & 13.67 \\
\hline \multicolumn{3}{|l|}{ Diastolic hypertension } \\
\hline No & 236 & 84.89 \\
\hline Yes & 42 & 15.11 \\
\hline \multicolumn{3}{|c|}{ Most recent (CD4+ cell count cells/ml) } \\
\hline$<200$ & 58 & 27.62 \\
\hline$\geq 200$ & 152 & 72.38 \\
\hline \multicolumn{3}{|l|}{ Viral load (copies/ml) } \\
\hline$<1000$ & 109 & 86.51 \\
\hline$\geq 1000$ & 17 & 13.49 \\
\hline \multicolumn{3}{|l|}{ ART Regimen } \\
\hline TDF/3TC/EFV & 271 & 97.48 \\
\hline TDF/3TC/ATV/r & 135 & 2.16 \\
\hline \multicolumn{3}{|l|}{ Random blood sugar } \\
\hline$<11.1 \mathrm{mmol} / \mathrm{l}$ & 275 & 98.92 \\
\hline$>11.1 \mathrm{mmol} / \mathrm{l}$ & 3 & 1.08 \\
\hline \multicolumn{3}{|c|}{ Protein present in urine } \\
\hline$\geq 2+$ (present) & 10 & 3.6 \\
\hline$<2+$ (absent) & 268 & 96.4 \\
\hline \multicolumn{3}{|l|}{ Nitrites in urine } \\
\hline Positive & 4 & 1.44 \\
\hline Negative & 274 & 98.56 \\
\hline \multicolumn{3}{|l|}{ Hematuria present } \\
\hline Present & 7 & 2.52 \\
\hline Absent & 271 & 97.48 \\
\hline \multicolumn{3}{|l|}{ Glucose in urine } \\
\hline Present & 2 & 0.72 \\
\hline Absent & 276 & 99.28 \\
\hline
\end{tabular}

urinalysis with a normal blood sugar. We found a low prevalence of $2.52 \%$. This is in agreement with other studies that show that use of TDF is associated with modest renal dysfunction.

Udeme et al 2018 in a systematic review and metaanalysis found an overall prevalence of CKD as $6.4 \%$. Chronic kidney disease was defined as eGFR $<60 \mathrm{ml} /$ min using any of the three formulas (i.e. Cockcroft, MDRD and CKD-EPI). In this study contributing factors
Table 3 Electrolyte abnormalities among study participants receiving TDF based ART $\geq 6$ months at Mulago Communicable Disease Clinic

\begin{tabular}{lll}
\hline Parameter & Frequency $(\mathrm{n})$ & Percentage $(\%)$ \\
\hline Phosphate(0.97-0.45 mmol/l) & & \\
Hypophosphatemia & 10 & 3.70 \\
Normal & 255 & 91.85 \\
Hyperphosphatemia & 12 & 4.44 \\
Potassium (3.5-5.0 mmol/l & & \\
Hypokalemia & 4 & 1.32 \\
Normal & 260 & 93.42 \\
Hyperkalemia & 15 & 5.26 \\
Calcium (2.2-2.7 mmol/l) & & \\
Hypocalcaemia & 43 & 15.44 \\
Normal & 233 & 83.89 \\
Hypercalcemia & 2 & 0.67 \\
\hline
\end{tabular}

included WHO region, hypertension and Diabetes Mellitus. Reid et al 2008 in a study (DART trial) done in Uganda and Zimbabwe, noted a prevalence of 7\% among patients on ART, followed up for 96 weeks. Majority (74\%) of the patients were receiving TDF based therapy. In this study Glomerular filtration rate was assessed using the Cockcroft gault formula which has its limitations.

The variability of different prevalence rates in the studies is attributable to; the different definitions of renal dysfunction, different methods used to estimate GFR and patient characteristics (age, ART regimen, advanced HIV and presence/absence of other co-morbidities) $[5,10,19]$.

The low prevalence in our study could be explained by the small sample size, being an outpatient clinic receiving not very critically sick patients, the possible effect of ART improving kidney function [20] and use of the CKD-Epi formula which is a more accurate method of assessing eGFR in asymptomatic patients compared to other formulas [17].

We assessed three serum electrolytes in this study namely; Potassium, Calcium and Phosphate. Albumin and vitamin $\mathrm{D}$ levels were not assessed. We noted mainly Hypocalcaemia (15.44\%), Hyperkalemia (15\%) and hypophosphatemia (3.59\%).Hypocalcaemia has been found at a higher prevalence in other studies among HIV infected patients compared to the general population. Vitamin D deficiency is very common among HIV patients and may be the most reasonable explanation $[21,22]$. TDF may cause vitamin D deficiency through impairment of tubular dysfunction leading to decreased 1-alpha hydroxylation of vitamin D and lower tubular reabsorption of vitamin $\mathrm{D}$ binding protein. There are also studies that have found an association with efavirenz use and low vitamin D levels which could also potentially explain the hypocalcaemia since $97 \%$ of their patients were on efavirenz. 
Table 4 EGFR calculated using the CKD-EPI formula to determine renal dysfunction among study participants on TDF for $\geq 6$ months at Mulago Communicable Disease Clinic

\begin{tabular}{llll}
\hline eGFR in $\mathrm{ml} / \mathrm{min} / 1.73 \mathrm{~m}^{2}$ & Frequency $(\mathrm{n})$ & Percentage (\%) & [95\%Conf.Interval] \\
\hline$<60$ & 7 & 2.52 & $(1.19-5.21)$ \\
$\geq 60$ & 271 & 97.48 & $(94.72-98.80)$ \\
eGFR values for different categories & & \\
$15-29$ & 1 & 0.36 \\
$30-59$ & 6 & 2.16 \\
$60-89$ & 51 & 18.35 \\
$\geq 90$ & 220 & 79.14 & \\
\hline
\end{tabular}

For patients with hypophosphatemia, data is similar to studies elsewhere that demonstrate that TDF is associated with Proximal tubulopathy manifesting as Fanconi syndrome [20, 23]. Rarely all the components of FS occur in one patient. Because of the wasting of Phosphate, potassium and amino acids in urine they tend to be low in serum. Hypophosphatemia could have a dual origin: decreased proximal reabsorption of phosphate and decreased vitamin D activation. Another possible cause of low phosphate in serum is the possibility of Vitamin D deficiency that is prevalent in HIV infected patients $[22,23]$. Hyperkalemia may be explained by the possibility of these patients having had acute kidney injury, chronic kidney disease and medications e.g.Cotrimoxazole [5, 24]. In this study majority of the patients were asymptomatic, though not enough information as regards symptoms was collected.

Proteinuria is an important marker of renal dysfunction, however for this study we tried to identify an operational definition that could in cooperate TDF nephrotoxicity. Other studies that have looked at proteinuria have given higher values of renal dysfunction. And this also helps capture the decline in renal dysfunction early to mitigate progress to ESRD.

Our study had some limitations; the small sample size (as a result we were unable to assess factors associated with renal dysfunction), missing information for some patients (e.g. CD4 and Viral load) which were not done/documented by primary health care giver and no baseline renal function to assess change over time (routine testing of renal function tests was no longer being done by the primary health care giver (findings from the DART trial) and we had limited time for the study to check the baseline levels). The results we got will form as baseline for future reference.

\section{Conclusions}

The prevalence of renal dysfunction among HIV infected patients receiving TDF was low at $2.52 \%$ and hypocalcaemia was the most common electrolyte abnormality noted. Renal dysfunction occurs at a low rate in our settings however when assessed should include serum electrolytes.

\section{Supplementary information}

Supplementary information accompanies this paper at https://doi.org/10. 1186/s12882-020-01873-y.

Additional file 1. The datasets generated and/or analyzed during the study are available in excel format and uploaded as supplemental information.

\section{Abbreviations}

AKI: Acute kidney injury; ART: Antiretroviral therapy; CKD: Chronic kidney disease; CKD: EPI Chronic Kidney Disease Epidemiology Collaboration; EGFR: Estimated glomerular filtration rate; FS: Fanconi syndrome; PLHIV: People living with HIV; TDF: Tenofovir disoproxil fumarate

\section{Acknowledgements}

The authors thank everyone who participated in this study. This study was a dissertation for a master's degree of medicine.

\section{Authors' contributions}

LN conceived the idea, collected data, interpreted the data \& drafted first version. LN, RK, ES, PB Designed the study, interpreted the data \& drafted first version. KS, LN- Analyzed the data. All authors reviewed the manuscript and approved the final version of the manuscript.

\section{Funding}

The work was supported by Mulago-KCCA project and Rashots. Both funders contributed money for the study i.e. concept through actual implementation of the study and printing of the final manuscript.

\section{Availability of data and materials}

All data generated or analysed during this study are included in this published article [and its supplementary information files].

\section{Ethics approval and consent to participate}

The study was approved by Department of Medicine of Makerere University College of health sciences, school of medicine, research \& ethics committee (SOMREC) and the Mulago hospital ethics committee. All participants provided written informed consent at enrollment. The consent process was administered in both English and local language determined by the preference of the participant.

\section{Consent for publication}

"Not applicable".

\section{Competing interests}

The authors declare that they have no competing interests.

\section{Author details}

${ }^{1}$ KCCA- directorate of public health, P.O. Box 7010, Kampala, Uganda. ${ }^{2}$ School of Medicine, Department of Internal Medicine, Makerere University College of Health Sciences, Kampala, Uganda. ${ }^{3}$ Panorama medical centre, Kampala, Uganda. 
Received: 3 November 2018 Accepted: 26 May 2020

Published online: 22 June 2020

\section{References}

1. Holmes MD, Dalal S, Volmink J, Adebamowo CA, Njelekela M, Fawzi WW, et al. Non-communicable diseases in sub-Saharan Africa: the case for cohort studies. PLoS Med. 2010;7(5):e1000244.

2. Haregu TN, Oldenburg B, Sestwe G, Elliott J, Nanayakkara V. Epidemiology of comorbidity of HIV/AIDS and non-communicable diseases in developing countries: a systematic review. J Global Health Care Syst. 2012;2:1.

3. Stanifer JW, Jing B, Tolan S, Helmke N, Mukerjee R, Naicker S, et al. The epidemiology of chronic kidney disease in sub-Saharan Africa: a systematic review and meta-analysis. Lancet Glob Health. 2014;2(3):e174-e81.

4. Naicker S. End-stage renal disease in sub-Saharan Africa. Kidney Int Suppl. 2013;3(2):161-3.

5. Campos P, Ortiz A, Soto K. HIV and kidney diseases: 35 years of history and consequences. Clin Kidney J. 2016:9:772 sfw104.

6. Wouters OJ, O'donoghue DJ, Ritchie J, Kanavos PG, Narva AS. Early chronic kidney disease: diagnosis, management and models of care. Nat Rev Nephrol. 2015;11(8):491.

7. Bastos MG, Kirsztajn GM. Chronic kidney disease: importance of early diagnosis, immediate referral and structured interdisciplinary approach to improve outcomes in patients not yet on dialysis. Jornal brasileiro de nefrologia. 2011;33(1):93-108.

8. HIV/AIDS JUNPO. 90-90-90: an ambitious treatment target to help end the AIDS epidemic. Geneva: UNAIDS; 2014.

9. Organization WH. Prevent HIV, test and treat all-WHO support for country impact. Progress report 2016. 2017.

10. Kim EJ, Ahn JY, Kim YJ, Wie S-H, Park DW, Song J-Y, et al. The prevalence and risk factors of renal insufficiency among Korean HIV-infected patients: the Korea HIV/AIDS cohort study. Infect Chemother. 2017;49(3):194-205.

11. DART. Routine versus clinically driven laboratory monitoring of HIV antiretroviral therapy in Africa (DART): a randomised non-inferiority trial. Lancet. 2010:375(9709):123.

12. Crum-Cianflone N, Ganesan A, Teneza-Mora N, Riddle M, Medina S, Barahona I, et al. Prevalence and factors associated with renal dysfunction among HIV-infected patients. AIDS Patient Care STDs. 2010;24(6):353-60.

13. Osafo C, Raji YR, Olanrewaju T, Mamven M, Arogundade F, Ajayi S, et al. Genomic approaches to the burden of kidney disease in sub-Saharan Africa: the human heredity and health in Africa (H3Africa) kidney disease research network. Kidney Int. 2016;90(1):2-5.

14. SCarPino M, Santoro M, PelliCanò G. HIV infection and kidney disease: literature review. Infect Dis Trop Med. 2015;1:e195.

15. Odongo P, Wanyama R, Obol JH, Apiyo P, Byakika-Kibwika P. Impaired renal function and associated risk factors in newly diagnosed HIV-infected adults in Gulu hospital, Northern Uganda. BMC Nephrol. 2015;16(1):43.

16. Wantakisha E, Chongwe G, Munkombwe D, Michelo C. Renal dysfunction among HIV-infected patients on tenofovir-based antiretroviral therapy at Ronald Ross Hospital in Zambia. J AIDS Clin Res. 2017:8:1.

17. Stevens LA, Coresh J, Greene T, Levey AS. Assessing kidney function-measured and estimated glomerular filtration rate. N Engl J Med. 2006;354(23):2473-83.

18. Gupta SK, Anderson AM, Ebrahimi R, Fralich T, Graham H, Scharen-Guivel V, et al. Fanconi syndrome accompanied by renal function decline with tenofovir disoproxil fumarate: a prospective, case-control study of predictors and resolution in HIV-infected patients. PLoS One. 2014;9(3):e92717.

19. Emem CP, Arogundade F, Sanusi A, Adelusola K, Wokoma F, Akinsola A. Renal disease in HIV-seropositive patients in Nigeria: an assessment of prevalence, clinical features and risk factors. Nephrology Dialysis Transplantation. 2007:23(2):741-6.

20. Michael J, Choi PCF, Patnaik A, Kleyman TR. Brief report :Trimethoprim induced hyperkalemia in a patient with AIDS; 1993.

21. Labarga P, Barreiro P, Martin-Carbonero L, Rodriguez-Novoa S, Solera C, Medrano J, et al. Kidney tubular abnormalities in the absence of impaired glomerular function in HIV patients treated with tenofovir. Aids. 2009;23(6): 689-96

22. McComsey GA, Tebas P, Shane E, Yin MT, Overton ET, Huang JS, et al. Bone disease in HIV infection: a practical review and recommendations for HIV care providers. Clin Infect Dis. 2010;51(8):937-46.
23. Tourret J, Deray G, Isnard-Bagnis C. Tenofovir effect on the kidneys of HIVinfected patients: a double-edged sword? J Am Soc Nephrol. 2013;24(10): 1519-27.

24. Choi MJ, Fernandez PC, Patnaik A, Coupaye-Gerard B, D'andrea D, Szerlip H, et al. Trimethoprim-induced hyperkalemia in a patient with AIDS. New England Journal of Medicine. 1993;328(10):703-6.

\section{Publisher's Note}

Springer Nature remains neutral with regard to jurisdictional claims in published maps and institutional affiliations.
Ready to submit your research? Choose BMC and benefit from:

- fast, convenient online submission

- thorough peer review by experienced researchers in your field

- rapid publication on acceptance

- support for research data, including large and complex data types

- gold Open Access which fosters wider collaboration and increased citations

- maximum visibility for your research: over $100 \mathrm{M}$ website views per year

At $\mathrm{BMC}$, research is always in progress.

Learn more biomedcentral.com/submissions 